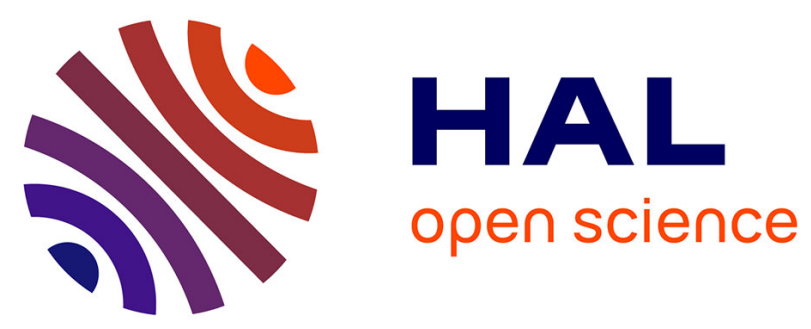

\title{
Patterns of Use, Safety, and Effectiveness of Targeted Therapies in First-Line Treatment of Metastatic Colorectal Cancer According to Age: The STROMBOLI Cohort Study
}

Amandine Gouverneur, J. Coutureau, J. Jove, M. Rouyer, A. Grelaud, S. Duc, Sébastien Gerard, D. Smith, A. Ravaud, C. Droz, et al.

\section{To cite this version:}

Amandine Gouverneur, J. Coutureau, J. Jove, M. Rouyer, A. Grelaud, et al.. Patterns of Use, Safety, and Effectiveness of Targeted Therapies in First-Line Treatment of Metastatic Colorectal Cancer According to Age: The STROMBOLI Cohort Study. Clinical Colorectal Cancer, 2019, 18 (1), pp.e150-e162. 10.1016/j.clcc.2018.11.005 . hal-03210810

\section{HAL Id: hal-03210810 https://hal.science/hal-03210810}

Submitted on 22 Oct 2021

HAL is a multi-disciplinary open access archive for the deposit and dissemination of scientific research documents, whether they are published or not. The documents may come from teaching and research institutions in France or abroad, or from public or private research centers.
L'archive ouverte pluridisciplinaire HAL, est destinée au dépôt et à la diffusion de documents scientifiques de niveau recherche, publiés ou non, émanant des établissements d'enseignement et de recherche français ou étrangers, des laboratoires publics ou privés.

\section{(ㄷ)(1) $\$$}

Distributed under a Creative Commons Attribution - NonCommerciall 4.0 International 
Patterns of use, safety and effectiveness of targeted therapies in first-line treatment of metastatic colorectal cancer according to age: the STROMBOLI cohort study

Amandine Gouverneur ${ }^{1,2,3}$, Juliette Coutureau ${ }^{1,3}$, Jérémy Jové ${ }^{2,4}$, Magali Rouyer ${ }^{2,4}$, Angela

Grelaud $^{2,4}$, Sophie Duc ${ }^{5}$, Stéphane Gérard ${ }^{6}$, Denis Smith ${ }^{7}$, Alain Ravaud ${ }^{7}$, Cécile Droz ${ }^{2,4}$, MarieAgnès Bernard $^{2,4}$, Régis Lassalle ${ }^{2,4}$, Annie Fourrier-Réglat ${ }^{1,2,3}$, Pernelle Noize ${ }^{1,2,3}$; on behalf the ETNA study group and the EREBUS study group

1 Univ. Bordeaux, Inserm, Bordeaux Population Health Research Center, team

PHARMACOEPIDEMIOLOGY, UMR 1219, F-33000 Bordeaux, France

2 Bordeaux PharmacoEpi, INSERM CIC1401, Bordeaux, France

3 CHU de Bordeaux, Pôle de Sante publique, Service de Pharmacologie médicale,

F-33000 Bordeaux, France

4 ADERA, F-33608 Pessac, France

5 Service de Gériatrie, CHU Bordeaux, Bordeaux, France

6 Service de Gériatrie, CHU Toulouse, Toulouse, France

7 Service d'Oncologie médicale, CHU Bordeaux, France

\section{Corresponding author}

Dr Amandine Gouverneur

Service de Pharmacologie Médicale

CHU et Université de Bordeaux

Zone Nord Carreire - Bâtiment 1A - Case 36

146 rue Léo Saignat 33076 Bordeaux Cedex, France

Tel. +33 (0)5 57574659

Fax. +33(0)5 57574660

E-mail: amandine.gouverneur@u-bordeaux.fr 


\begin{abstract}
Background

Metastatic colorectal cancer (mCRC) is increasingly treated using targeted therapies. Their real-life evaluation is insufficient, especially in elderly and frail patients. The aim was to describe use, safety, and effectiveness of targeted therapies in first-line mCRC treatment according to age. Materials and Methods
\end{abstract}

Two field cohorts of patients initiating bevacizumab or cetuximab for first-line mCRC were pooled. Patients characteristics, use and safety were compared between younger and elderly patients $(<75 v s$ $\geq 75$ years). 2-year overall survival (OS) and progression-free survival (PFS) were estimated in both age groups using the Kaplan-Meier method adjusted on factors associated with death or progression identified with Cox multivariate modeling.

Results

800 patients (51.4\% bevacizumab) were included: $62.3 \%$ male, median age 64 years, $14.8 \%$ ECOG$\mathrm{PS} \geq 2$. Elderly patients $(15.8 \%)$ were more often treated with 5-fluorouracil alone than younger. Severe adverse events were equivalent across age groups. ECOG-PS $\geq 1$, abnormal hemoglobin and abnormal alkaline phosphatases were associated with a higher risk of death; OS adjusted on these factors was similar between elderly and younger patients. ECOG-PS $\geq 1$, lung metastases, abnormal hemoglobin and abnormal creatinine clearance were associated with a higher risk of progression or death; PFS adjusted on these factors was similar across groups.

\title{
Conclusion
}

Despite treatment adaptations, elderly patients could benefit from targeted therapies as younger without safety warning. 
MicroAbstract: Elderly patients are excluded from clinical trials, yet they can be treated in clinical practice. This large cohort of metastatic colorectal cancer patients treated in first-line with targeted therapies reinforces their benefit in elderly patients. Targeted therapies safety and effectiveness are similar between elderly and younger metastatic colorectal cancer patients.

Clinical Practice Points: Bevacizumab or cetuximab combined with chemotherapy has demonstrated improved survival outcomes in first-line mCRC treatment. In real-life settings, the use of bevacizumab or cetuximab in elderly mCRC patients resulted in outcomes close to those in younger patients. After adjustment, there was no difference between elderly and younger patients in terms of OS (median 23.4 months 95\%CI [21.7; -] vs 21.7 months [17.8; -], p=0.45) and in terms of PFS (median 9.4 months [8.8; 9.8] vs 9.7 months [8.7; 10.9], $\mathrm{p}=0.59)$.

An older age was not a risk factor of death or progression. An ECOG PS $\geq 1$, lung metastases, abnormal hemoglobin, abnormal alkaline phosphatases, and abnormal creatinine clearance were risk factors of death or progression.

Treatment by bevacizumab or cetuximab with chemotherapy as first-line therapy represents an option in therapeutic strategy of $\mathrm{mCRC}$ in real-life practice for elderly patients.

Keys word: molecular targeted therapy; colorectal neoplasm; neoplasm metastasis; aged; frail elderly 


\section{INTRODUCTION}

Colorectal cancer (CRC) is one of the most common cancers worldwide. It is more frequent among the elderly; nearly one third of incident cases are diagnosed in patients aged 75 years or over. ${ }^{1}$ At diagnosis, $20 \%$ of patients have metastases, and approximately $40 \%$ will at one point have metastatic CRC (mCRC). ${ }^{2,3}$ Since 2005, targeted therapies have become available and recommended for the treatment of $\mathrm{mCRC}$, in combination with chemotherapy. ${ }^{4,5}$ The bevacizumab, an antibody targeting Vascular Endothelial Growth Factor (VEGF) and the cetuximab, an antibody targeting Epidermal Growth Factor Receptor (EGFR) are the most frequently used in first-line treatment. $^{4,5}$

Clinical trials of targeted therapies in mCRC suffer from an underrepresentation of elderly patients and only provide information on middle-aged healthy subjects fit to undergo treatment with anticancer medications. ${ }^{6}$ In routine clinical practice, targeted therapies may be prescribed to patients who would be excluded from clinical trials because of advanced age or other frailty parameters (e.g. comorbidities). As a consequence, observational studies are necessary to fill this gap in evaluation. The aim of the STROMBOLI study was to describe the use, safety, and effectiveness of targeted therapies used in first-line mCRC treatment in a real-life setting according to age. 


\section{MATERIALS AND METHODS}

\section{Study design and population}

The STROMBOLI cohort corresponds to the pooled population of two existing observational cohorts: ETNA and EREBUS. Details on the ETNA and EREBUS studies have been reported

elsewhere. ${ }^{7,8}$ Briefly, ETNA was an observational cohort study conducted in 28 public and private clinical centers of Southwest France. All patients who initiated bevacizumab between January 2006 and December 2007 were identified using nominative dispensations from hospital pharmacies. Patients treated for first-line mCRC with inoperable metastases were included and followed for 2 years after initiation of first-line therapy. EREBUS was an observational cohort study conducted in 65 public and private clinical centers of France. All patients who initiated cetuximab between January 2009 and December 2010 were identified using the same process as for the ETNA cohort. Patients treated for first-line mCRC with inoperable metastases and KRAS wild-type status were included and followed for 2 years after initiation of first-line therapy.

Before inclusion in the ETNA and EREBUS cohorts, patients were informed of the study objectives and data collection, and could indicate their wish not to participate. The STROMBOLI study protocol was approved by the French data protection agencies. In accordance with French regulations for observational studies applicable at the time of the study conception, ethics committee approval was not required.

\section{Available data}

Data extracted from patients medical records at baseline and during follow-up of both cohorts were pooled. Baseline characteristics included demographic data, history of CRC (primary tumor and metastatic disease), significant medical history, as well as clinical and biological exams before initiation of first-line therapy. During the 2 years of follow-up, patterns of bevacizumab or cetuximab use in first-line therapy were collected including doses, timing of administration, 
combined chemotherapy, as well as adverse events occurring at each treatment cycle, treatment response, and subsequent treatment lines (with or without targeted therapy).

Adverse events documented in the medical files were classified according to the National Cancer Institute Common Terminology Criteria for Adverse Events (NCI-CTCAE), version 3.0. ${ }^{9}$ Treatment response evaluation in current practice by CT-scan every 2 to 3 months was based on the Response Evaluation Criteria in Solid Tumors (RECIST). ${ }^{9,10}$

\section{Statistical analyses}

Descriptive analyses were performed to compare baseline characteristics, use and safety of targeted therapies between younger and elderly patients ( $<75$ years $v s \geq 75$ years). Categorical variables were compared across groups using Pearson's chi-square test, or Fisher's exact chi-square test where appropriate. Continuous variables were compared across groups using Student t-test.

Survival analyses included two steps. Firstly, factors associated with death or progression were identified as follows. The list of all potential poor prognosis factors available was established in agreement with two clinicians (see Appendices for details). Cox proportional hazards modeling was used to identify the factors independently associated with death or progression providing hazard ratios $(\mathrm{HR})$ with $95 \%$ confidence intervals $(95 \% \mathrm{CI})$. The baseline was the initiation of the first-line therapy and the follow-up was censored at death or progression, loss to follow-up, or the end of the study period whichever came first. For variables with $>10 \%$ of missing data, a multiple imputation by Markov Chain Monte Carlo was performed. ${ }^{11}$ All variables associated with a $\mathrm{p}<0.25$ in univariate analyses were included in an initial multivariate model, and the less significantly associated variables successively removed to keep only those associated with a $p<0.05$. However, to minimize confounding, age and sex were systematically kept in the model.

Secondly, Overall Survival (OS) and Progression-Free Survival (PFS) were estimated in both age groups using the Kaplan-Meier method. OS was defined as the interval between start of first-line 
therapy and death from any cause and PFS as the interval between start of first-line therapy and first disease progression or death. To avoid channeling, these survival analyses were adjusted on factors identified as associated with death or progression in multivariate Cox proportional hazards modeling. Median OS and PFS estimates along with their 95\% CI were reported, as well as 2-year OS and PFS rates (with 95\%CI). OS or PFS were compared across groups using the log rank test. All analyses were performed using SAS® statistical software (SAS Institute, version 9.4, Cary, NC). 


\section{RESULTS}

\section{Study population characteristics}

A total of 800 patients were included in the STROMBOLI cohort, $411(51.4 \%)$ were treated with bevacizumab and $389(48.6 \%)$ with cetuximab. The median age was 64.0 years [InterQuartile Range (IQR): 58.0-72.0]; 126 patients (15.8\%) were $\geq 75$ years old, $498(62.3 \%)$ were male and 585 (73.1\%) had a primary tumor in the colon. The Eastern Cooperative Oncology Group Performance Status (ECOG-PS) was $\geq 2$ for 118 patients $(14.8 \%)$ and $361(45.1 \%)$ had at least one cardiovascular disorder. Most patients $(73.5 \%)$ received irinotecan-based chemotherapy regimen in combination with targeted therapy and more than one-third (35.6\%) had at least one dose reduction of targeted therapy. Definitive discontinuation of first-line therapy was observed in $84.1 \%$ of patients, nearly two-thirds due to progressive disease $(63.9 \%)$ and $8.3 \%$ to poor tolerability. The incidence of grade $3 / 4$ adverse events was $52.0 \%$, most frequently asthenia (10.5\%), diarrhea (9.3\%) and neutropenia $(8.9 \%)$.

\section{Descriptive analyses stratified according to age}

ECOG-PS $\geq 1$ and denutrition were significantly more frequent in elderly patients in comparison to younger patients $(65.0 \%$ vs $53.0 \%, \mathrm{p}=0.005$ and $13.5 \%$ vs $6.7 \%, \mathrm{p}=0.007$, respectively). Among medical history, cardiac and renal disorders were significantly more frequent in elderly patients $(60.3 \%$ vs $42.3 \%, \mathrm{p}=0.0002$ and $10.3 \%$ vs $4.7 \%, \mathrm{p}=0.01$ respectively) as well as anemia $(57.9 \%$ vs 48.1\%, $\mathrm{p}=0.04$; Table 1).

Regarding treatment patterns, elderly patients were more often treated with 5-fluorouracil alone in combination with bevacizumab or cetuximab $(6.4 \%$ vs $0.5 \%, \mathrm{p}=0.0003)$. There was no difference in the delay between the chemotherapy and targeted therapy initiation between age groups but elderly patients had less frequently dose reductions in comparison to younger patients $(28.6 \% \mathrm{vs} 38.4 \%$, $\mathrm{p}=0.01$ ). There was no difference between elderly and younger patients regarding definitive 
discontinuation of first-line therapy $(86.5 \%$ vs $83.7 \%, \mathrm{p}=0.17)$; however, elderly patients seemed to have less frequently a second-line treatment $(58.8 \%$ vs $67.1 \%, \mathrm{p}=0.08)$.

Among any-grade adverse events, nervous system disorders and skin and subcutaneous tissue disorders were less frequent in elderly patients $(37.4 \%$ vs $23.8 \%, \mathrm{p}=0.003$ and $55.0 \%$ vs $43.7 \%$, $\mathrm{p}=0.02$, respectively). In terms of grade $3 / 4$ adverse events, there was no significant difference between age groups (Table 2).

\section{Survival analyses}

After 2 years of follow-up, 404 patients $(50.5 \%)$ had died. After univariate Cox proportional hazards analyses (see Appendices Table A), the ECOG-PS, the body mass index (BMI), the primary tumor site, the type of metastases and all tested biological parameters were included in the multivariate model. After adjustment on age and sex, ECOG-PS $\geq 1$, abnormal hemoglobin and abnormal alkaline phosphatases were found to be associated with a higher risk of death in multivariate analyses (Table 3). There was no difference between elderly and younger patients in terms of OS (median 23.4 months 95\%CI [21.7; -] vs 21.7 months [17.8; -], p=0.45; Figure 1), in Kaplan-Meier method adjusted on ECOG-PS, hemoglobin and alkaline phosphatases.

After 2 years of follow-up, $712(89.0 \%)$ had disease progression or had died. After univariate Cox proportional hazards analyses (see Appendices Table B), the ECOG-PS, the BMI, the number of metastatic sites, the lung metastases and all tested biological parameters except bilirubin were included in the multivariate model. After adjustment on age and sex, ECOG-PS $\geq 1$, lung metastases, abnormal hemoglobin and abnormal creatinine clearance were found to be associated with a higher risk of progression or death in multivariate analyses (Table 4). There was no difference between elderly and younger patients in terms of PFS (median 9.4 months 95\%CI [8.8; 9.8] vs 9.7 months [8.7; 10.9], $\mathrm{p}=0.59$; Figure 2). OS and PFS rates were reported in Appendices Table C. 


\section{DISCUSSION}

The STROMBOLI study is one of the largest observational cohorts of patients treated with the two major targeted therapies available in first-line for mCRC treatment. Its strength is to provide data on all useful aspects for post-marketing evaluation (i.e. use, effectiveness and safety) in 800 patients, especially patients that would have been excluded from clinical trials: patients with an ECOGPS $\geq 2$ (14.8\%), with cardiovascular comorbidities (45.1\%) or with biological abnormalities (low hemoglobin $49.6 \%$ or low creatinine clearance $16.3 \%$ ).

The main interest of this cohort analysis is the comparison performed between the younger and elderly patients. If age seems to be a factor driving the patterns of use (e.g. 5-fluorouracil alone, second-line treatment), it was not associated with a different safety profile nor a lower effectiveness in terms of survival outcomes. In the BRITE cohort, studying bevacizumab only, four age groups were compared: $<65$ years, 65 to 74 years, 75 to 79 years and $\geq 80$ years. If median PFS was similar across all age groups (ranging from 8.6 to 10.0 months), median OS was only different between patients aged $\geq 80$ years and those aged $<75$ years (ranging from 16.8 to 24.6 months). Except for arterial thromboembolic events which were more frequently reported in patients aged $\geq 75$ years, the safety profile was equivalent across all age groups. ${ }^{12,13}$ Finally, our results confirm that the use of targeted therapies in the elderly population is effective and safe in real-life setting. However, even if the present cohort included $15 \%$ of patients aged $\geq 75$ years, in comparison to around $8 \%$ in clinical trials, the median age was comparable to the median age of clinical trials (around 64 years). ${ }^{6}$ This suggests that elderly patients treated with targeted therapies in clinical practice may be still selected according to good prognostic factors. This median age was consistent with that found in other postmarketing studies on targeted therapies in MCRC: an international pharmacovigilance study and other observational cohorts. ${ }^{14,12,15}$ The next step would be to investigate determinants of treatment with targeted therapies in the whole elderly population with mCRC to assess if there is a real undertreatment of certain elderly patients. ${ }^{16}$ Indeed, in an Australian cohort studying the use of 
chemotherapy and bevacizumab in patients aged $\geq 65$ years, three factors were associated with no treatment by bevacizumab: age ( $\geq 75$ years), type of center (public or private hospital) and Charlson comorbidity index $(\geq 3)$; yet, not ECOG-PS $\geq 2 .^{17}$

Another interest of this cohort was to identify factors associated with death or progression in a large and homogeneous population of mCRC patients treated with targeted therapies in first-line therapy. In fact, age and comorbidities are frequently associated with the idea that these patients are vulnerable and cannot benefit from anticancer medications. The present study does not found that older age was a risk factor of death or progression and among all other tested vulnerability factors that are often considered in rapid detection tools of frailty (e.g. denutrition, comorbidities) none were found to be associated with a higher risk of death or progression, except creatinine clearance associated with progression or death. ${ }^{18,19}$ This could be explained by the prescribing of lower doses of anticancer medications in patients with altered kidney function. Unfortunately, available data were not sufficiently accurate to confirm this hypothesis. All other criteria were rather related to the mCRC: ECOG-PS, lung metastases, abnormal hemoglobin (potential marker of bleeding) and abnormal alkaline phosphatases (potential marker of liver metastases). The prognostic score proposed by Köhne et al. before the area of targeted therapies included four factors associated with early death: ECOG-PS, number of metastatic sites, abnormal alkaline phosphatases and low white blood cells count. ${ }^{20}$ More recently, Kabbinavar et al. ${ }^{21}$ showed that this score could be extended to patients treated with bevacizumab in association with 5-fluorouracil-based regimen while Desot et $a l^{22}$ found that ECOG-PS and low white blood cells count could be sufficient to classify patients at risk of death in a study including patients treated with bevacizumab, cetuximab or panitumumab. As in the present study, ECOG-PS is highlighted as a risk factor in most of evaluations. One explanation could be that this score explains some other frailty aspects (such as denutrition or comorbidities). Indeed, in a study evaluating whether Comprehensive Geriatric Assessment (CGA) add further information with respect to the ECOG-PS in elderly cancer patients, components of the 
CGA, especially Activities of Daily Living and Instrumental Activities of Daily Living and ECOGPS were strongly correlated. ${ }^{23}$ Even if ECOG-PS alone cannot be sufficient to detect patients who will not benefit from treatment, all these data show that this is an important factor to take into account especially since it is systematically evaluated by the oncology community.

To conclude, elderly patients could benefit from treatment by targeted therapies without safety warning. However, further studies are needed to understand better treatment determinants in this population and screen more efficiently elderly patients that should be treated by targeted therapies. 


\section{Acknowledgements}

The authors wish to thank the ETNA study group that included: D. Smith-CHU Bordeaux, N. Tubiana-Mathieu - CHU Limoges, P. Michel - CHU Rouen, R. Guimbaud - CHU Toulouse, Y. Becouarn - Institut Bergonié Bordeaux, F. Viret - Institut Paoli-Calmettes Marseille, R. Guimbaud Institut Claudius Regaud Toulouse, D. Larregain-Fournier - CH Bayonne, Y. Botreau - CH Cahors, P. Texereau - CH Mont de Marsan, D. Auby - CH Libourne, L. Gautier-Felizot - CH Dax, I. LouryLarivière - CH Pau, E. Brudieux - CH Villeneuve sur Lot, L. Cany - Polyclinique Francheville Périgueux, C. Lecaille - Polyclinique Bordeaux Nord, D. Jaubert - Clinique Tivoli Bordeaux, P. Guichard - Polyclinique Bordeaux Rive Droite, O. Bernard - Clinique Calabet Agen, L. Vives - CH Saint Gaudens, N. Taoubi - CH Ville-franche de Rouergue, M. Martinez - Clinique du Parc Toulouse, F. Burki - Clinique de l'Union Toulouse, I. Roque - Clinique des Cèdres Cornebarrieu, F. Thouveny - Clinique du Pont de Chaume Montauban and MH. Gaspard - Clinique Claude Bernard Albi.

The authors wish to thank the EREBUS study group that included: Clinique Calabet - Agen, Clinique de l'Europe - Amiens, Centre P. Papin - Angers, Clinique générale d'Annecy, CH d'Argenteuil, $\mathrm{CH}$ d'Auxerre, $\mathrm{CH}$ de Bar Le Duc, $\mathrm{CH}$ de Bastia, $\mathrm{CH}$ de Bayonne, Clinique Paulmy Bayonne, CHU de Besançon, CH de Blois, Polyclinique Bordeaux Nord, Hôpital St André Bordeaux, Institut Bergonié - Bordeaux, Clinique Tivoli - Bordeaux, CH de Brive, Polyclinique St Jean - Cagnes sur Mer, CH de Cannes, $\mathrm{CH}$ de Carcassonne, CHU de Clermont-Ferrand, CH de Cognac, CH de Dax, CHU de Dijon, Centre médical de Forcilles - Ferolles-Attilly, Clinique Sainte Marguerite - Hyères, $\mathrm{CH}$ de La Roche sur Yon, $\mathrm{CH}$ de La Rochelle, CHU de Grenoble, CH du Chesnay, $\mathrm{CH}$ du Coudray, $\mathrm{CH}$ du Mans, $\mathrm{CH}$ de Libourne, CHU de Limoges, Clinique de la Sauvegarde - Lyon, CH St Joseph - Marseille, Hôpital Beauregard - Marseille, CH de Montauban, CH de Mont de Marsan, CHU de Montbéliard, CH de Montélimar, Centre Val d'Aurelle Montpellier, Centre Azuréen de Cancérologie - Mougins, CH de Nevers, CHU de Nice, Centre A. Lacassagne - Nice, Hôpital Cochin - Paris, CH de Pau, Polyclinique Francheville - Périgueux, Hôpital Haut-Lévêque - Pessac, CHU de Poitiers, CH de Rambouillet, CH de Roubaix, CHU de Rouen, Clinique Armoricaine de Radiologie - St Brieuc, CH Privé de la Loire - St Etienne, Institut de Cancérologie de la Loire - St Priest en Jarez, Polyclinique de l'Ormeau - Tarbes, CHI de Toulon, Hôpital Purpan - Toulouse, Hôpital Rangueuil - Toulouse, CHU de Tours, CHU de Valenciennes, CH de Vannes, Hôpital P. Brousse - Villejuif.

Funding source: The present additional analyses were not supported by any grant.

The ETNA cohort was supported by partial funding from the French National Clinical Research Programme (Programme Hospitalier de Recherche Clinique) from the French Ministry of Health 
[grant number 2005/PHRC/INCa/DHOS], and an additional unconditional grant from Roche SAS, manufacturers of bevacizumab, who had no role in study design; in the collection, analysis, and interpretation of data; in the writing of the report; and in the decision to submit the report for publication. The EREBUS cohort was supported by an unconditional grant from Merck Santé s.a.s. (37, rue St Romain, 69008 Lyon 1, France).

Conflict of interest statement: MR reports grants from The Pharmacoepidemiology unit has received research funding and unconditional grants that have contributed indiscriminately to the salaries of its employees, notably from: Abott, Aptalis, AstraZeneca, Bayer, Baxter, Biogen, BMS, Boehringer, Erempharma, Helsinn, Janssen-Cilag, Lilly, Lunbeck, Merck Serono, Novartis, Nycomed, Pierre Fabre, Sanofi, Stallergenes, Vifor, outside the submitted work. The other authors have declared no conflicts of interest related to this work. 


\section{REFERENCES}

1 Siegel RL, Miller KD, Fedewa SA, et al. Colorectal cancer statistics, 2017. CA Cancer J Clin 2017; 67: 177-193.

2 Howlader N, Noone A, Krapcho M, et al. SEER Cancer Statistics Review, 1975-2014, National Cancer Institute. Bethesda, MD. Based on November 2016 SEER data submission, posted to the SEER web site, April 2017. Available at http://seer.cancer.gov/csr/1975_2014/sections.html. Accessed March 19, 2018.

3 Del Rio M, Mollevi C, Vezzio-Vie N, et al. Specific extracellular matrix remodeling signature of colon hepatic metastases. PloS One 2013; 8: e74599.

4 Papamichael D, Audisio R, Glimelius B, et al. Treatment of colorectal cancer in older patients: International Society of Geriatric Oncology (SIOG) consensus recommendations 2013. Ann Oncol 2015; 26: 463-476.

5 Van Cutsem E, Cervantes A, Adam R, et al. ESMO consensus guidelines for the management of patients with metastatic colorectal cancer. Ann Oncol 2016; 27: 1386-1422.

6 Gouverneur A, Salvo F, Berdaï D, et al. Inclusion of elderly or frail patients in randomized controlled trials of targeted therapies for the treatment of metastatic colorectal cancer: A systematic review. J Geriatr Oncol 2018; 9: 15-23.

7 Fourrier-Réglat A, Smith D, Rouyer M, et al. Survival outcomes of bevacizumab in first-line metastatic colorectal cancer in a real-life setting: results of the ETNA cohort. Target Oncol 2014; 9: $311-319$.

8 Rouyer M, François E, Cunha AS, et al. Effectiveness of cetuximab as first-line therapy for patients with wild-type KRAS and unresectable metastatic colorectal cancer in real-life practice: results of the EREBUS Cohort. Clin Colorectal Cancer 2018; 17: 129-139.

9 NCI-CTCAE v3.0. Cancer Therapy Evaluation Program, Common Terminology Criteria for Adverse Events, Version 3.0. 2006. Available at https://ctep.cancer.gov/protocolDevelopment/electronic_applications/docs/ctcaev3.pdf. Accessed 
May 30, 2018.

10 Therasse P, Arbuck SG, Eisenhauer EA, et al. New Guidelines to Evaluate the Response to Treatment in Solid Tumors. J Natl Cancer Inst 2000; 92: 205-216.

11 Rubin DB. Multiple Imputation after 18+ Years. J Am Stat Assoc 1996; 91: 473-489.

12 Kozloff M, Berlin J, Flynn P, et al. Clinical outcomes in elderly patients with metastatic colorectal cancer receiving bevacizumab and chemotherapy: results from the BRiTE observational cohort study. Oncology 2010; 78: 329-339.

13 Jehn CF, Böning L, Kröning H, et al. Influence of comorbidity, age and performance status on treatment efficacy and safety of cetuximab plus irinotecan in irinotecan-refractory elderly patients with metastatic colorectal cancer. Eur J Cancer 2014; 50: 1269-1275.

14 Gouverneur A, Claraz P, Rousset M, et al. Comparative Safety of Targeted Therapies for Metastatic Colorectal Cancer between Elderly and Younger Patients: a Study Using the International Pharmacovigilance Database. Target Oncol 2017; 12: 805-814.

15 Jehn C, Böning L, Kröning H, et al. Cetuximab-based therapy in elderly comorbid patients with metastatic colorectal cancer. Br J Cancer 2012; 106: 274-8.

16 Keikes L, Oijen MGH van, Lemmens VEPP, et al. Evaluation of Guideline Adherence in Colorectal Cancer Treatment in The Netherlands: A Survey Among Medical Oncologists by the Dutch Colorectal Cancer Group. Clin Colorectal Cancer 2018 ;17: 58-64.

17 Parakh S, Wong H, Rai R, et al. Patterns of care and outcomes for elderly patients with metastatic colorectal cancer in Australia. J Geriatr Oncol 2015; 6: 387-394.

18 Saliba D, Elliott M, Rubenstein LZ, et al. The Vulnerable Elders Survey: a tool for identifying vulnerable older people in the community. J Am Geriatr Soc 2001; 49: 1691-1699.

19 Soubeyran P, Bellera C, Goyard J, et al. Screening for vulnerability in older cancer patients: the ONCODAGE Prospective Multicenter Cohort Study. PloS One 2014; 9: e115060.

20 Köhne C-H, Cunningham D, Di Costanzo F, et al. Clinical determinants of survival in patients with 5-fluorouracil- based treatment for metastatic colorectal cancer: results of a multivariate 
analysis of 3825 patients. Ann Oncol 2002; 13: 308-317.

21 Kabbinavar F, Irl C, Zurlo A, et al. Bevacizumab improves the overall and progression-free survival of patients with metastatic colorectal cancer treated with 5-fluorouracil-based regimens irrespective of baseline risk. Oncology 2008; 75: 215-23.

22 Desot E, de Mestier L, Volet J, et al. Prognostic factors in patients with non resectable metastatic colorectal cancer in the era of targeted biotherapies: relevance of Köhne's risk classification. Dig Liver Dis 2013; 45: 330-335.

23 Repetto L, Fratino L, Audisio RA, et al. Comprehensive geriatric assessment adds information to Eastern Cooperative Oncology Group performance status in elderly cancer patients: an Italian Group for Geriatric Oncology Study. J Clin Oncol 2002; 20: 494-502. 


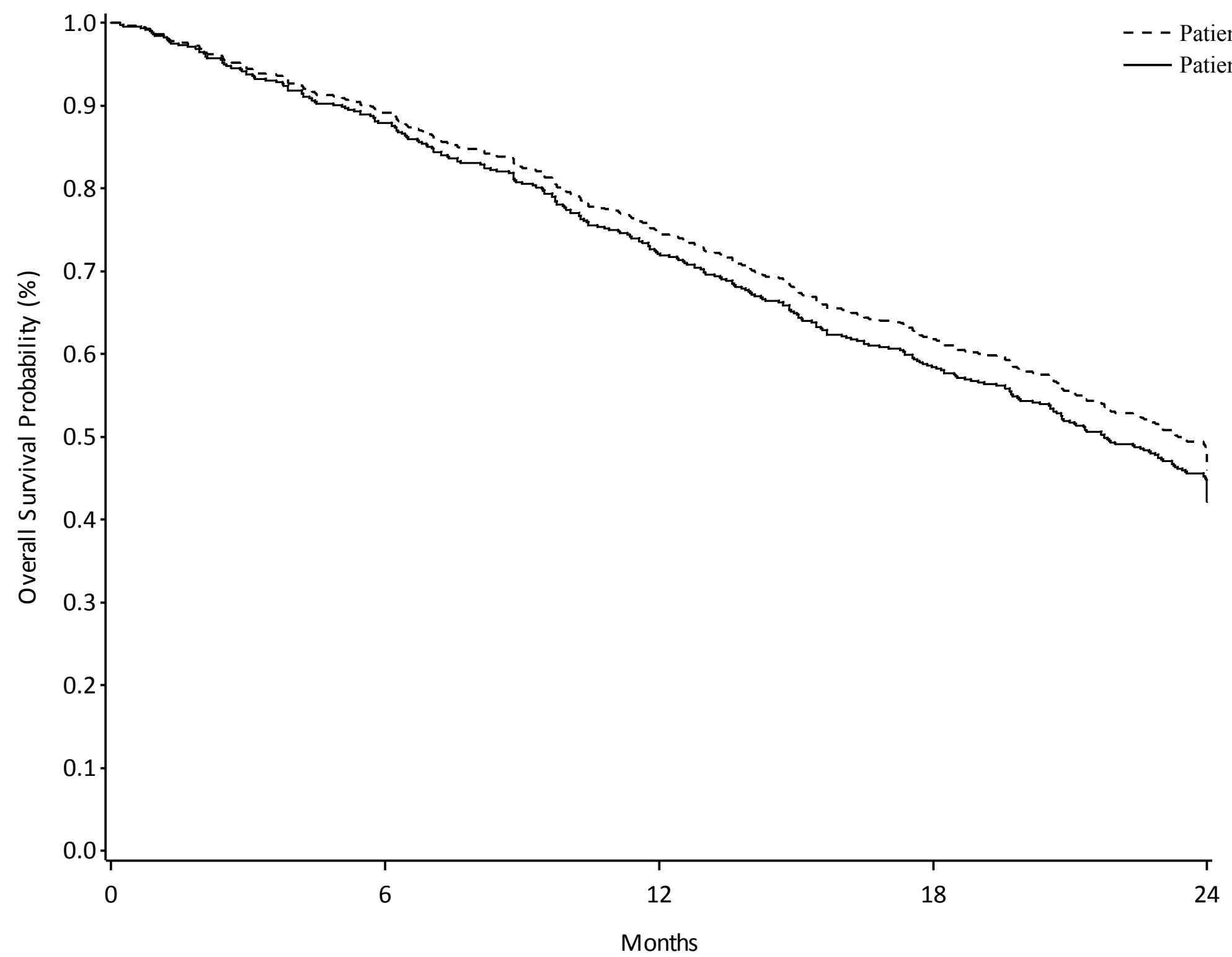

Figure 1: Overall survival (OS) during the 2 years after inclusion stratified according to age ( $<75$ years $v s \geq 75$ years; adjusted Kaplan-Meier curve) 


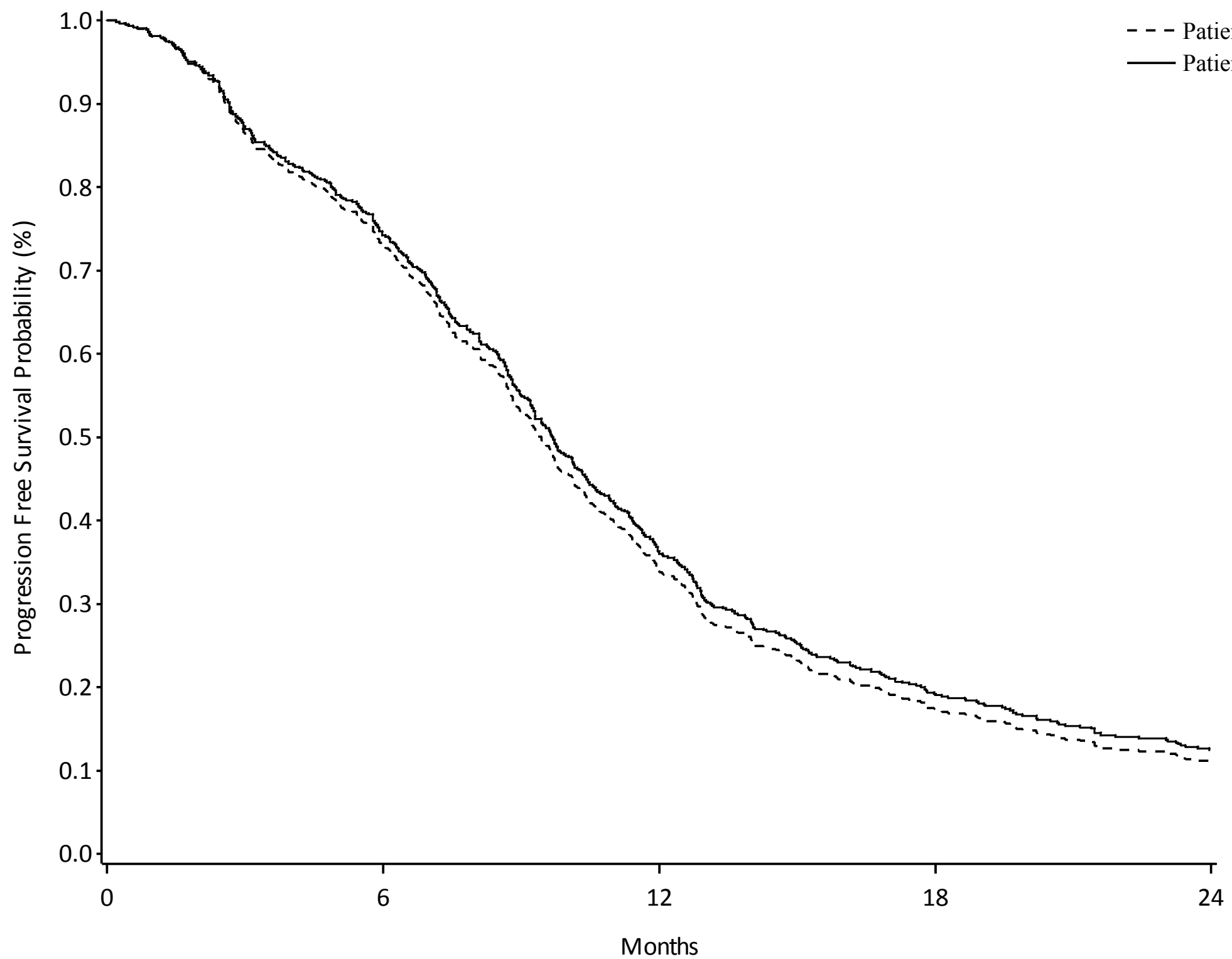

Figure 2: Progression free survival (PFS) during the 2 years after inclusion stratified according to age ( $<75$ years $v s \geq 75$ years; adjusted Kaplan-Meier curve) 
Table 1. Baseline demographic and clinical characteristics according to age in the

STROMBOLI study $(\mathrm{n}=\mathbf{8 0 0})$

\begin{tabular}{|c|c|c|c|}
\hline Characteristics, $n(\%)$ & $\begin{array}{c}\text { Patients aged }<75 \\
\text { years, } n=674\end{array}$ & $\begin{array}{c}\text { Patients aged } \geq 75 \\
\text { years, } n=126\end{array}$ & $p$ \\
\hline Age, years - median [IQR] & $62.0[57.0-68.0]$ & $77.0[76.0-80.0]$ & $<0.0001$ \\
\hline Male & $414(61.4)$ & $84(66.7)$ & 0.27 \\
\hline ECOG-PS & & & 0.005 \\
\hline 0 & $270(40.1)$ & $31(24.6)$ & \\
\hline 1 & $264(39.2)$ & $57(45.2)$ & \\
\hline$\geq 2$ & $93(13.8)$ & $25(19.8)$ & \\
\hline Missing data & $47(7.0)$ & $13(10.3)$ & \\
\hline Body mass index (BMI) ${ }^{a}$ & & & 0.007 \\
\hline Normal & $608(90.2)$ & $103(81.7)$ & \\
\hline Denutrition & $45(6.7)$ & $17(13.5)$ & \\
\hline Missing data & $21(3.1)$ & $6(4.8)$ & \\
\hline Synchronous metastases & $487(72.3)$ & $82(65.1)$ & 0.10 \\
\hline \multicolumn{4}{|l|}{ Metastasis localization ${ }^{b}$} \\
\hline Liver & $501(74.3)$ & $94(74.6)$ & 0.95 \\
\hline Lung & $200(29.7)$ & $37(29.4)$ & 0.94 \\
\hline Peritoneum & $147(21.8)$ & $24(19.0)$ & 0.49 \\
\hline Lymph node & $147(21.8)$ & $21(16.7)$ & 0.19 \\
\hline Other & $97(14.4)$ & $14(11.1)$ & 0.33 \\
\hline Number of metastatic sites & & & 0.12 \\
\hline 1 & $367(54.5)$ & $73(57.9)$ & \\
\hline 2 & $214(31.8)$ & $44(34.9)$ & \\
\hline$\geq 3$ & $93(13.8)$ & $9(7.1)$ & \\
\hline \multicolumn{4}{|l|}{ Medical history } \\
\hline Cardiovascular disorders & $285(42.3)$ & $76(60.3)$ & 0.0002 \\
\hline Nervous disorders & $64(9.5)$ & $7(5.6)$ & 0.15 \\
\hline Renal disorders & $32(4.7)$ & $13(10.3)$ & 0.01 \\
\hline Abnormal hemoglobin & $324(48.1)$ & $73(57.9)$ & 0.04 \\
\hline Abnormal creatinine clearance & $81(12.0)$ & $49(38.9)$ & $<0.0001$ \\
\hline
\end{tabular}


Table 2. Description of targeted therapy usage patterns in first-line therapy at 2 years of

follow-up in the STROMBOLI study $(n=800)$

\begin{tabular}{|c|c|c|c|}
\hline Characteristics, $n(\%)$ & $\begin{array}{c}\text { Patients aged } \\
<75 \text { years, } n=674\end{array}$ & $\begin{array}{c}\text { Patients aged } \\
\geq 75 \text { years, } n=126\end{array}$ & $p$ \\
\hline First-line chemotherapy used with targeted therapy & & & 0.0003 \\
\hline Irinotecan based regimen & $486(72.1)$ & $92(73.0)$ & \\
\hline Oxaliplatin based regimen & $171(25.4)$ & $25(19.8)$ & \\
\hline Irinotecan and oxaliplatin based regimen & $10(1.5)$ & $0(0.0)$ & \\
\hline 5-fluorouracil alone & $4(0.5)$ & $8(6.4)$ & \\
\hline No chemotherapy & $3(0.8)$ & $1(0.8)$ & \\
\hline Initiation of the targeted therapy & & & 0.95 \\
\hline At the $1^{\text {st }}$ cycle of treatment & $414(61.4)$ & $77(61.1)$ & \\
\hline Delayed targeted therapy initiation & $260(38.6)$ & 49 (38.9) & \\
\hline Delay, days - median [range] & $28[14.0-41.5]$ & $28[18.0-43.0]$ & 0.55 \\
\hline At least one dose reduction & & & 0.01 \\
\hline None & $343(50.9)$ & $77(61.1)$ & \\
\hline At least one & $249(38.4)$ & $36(28.6)$ & \\
\hline Missing data & $82(12.2)$ & $13(10.3)$ & \\
\hline Number of cycles - median [IQR] & $12[7-16]$ & $12[5-18]$ & 0.85 \\
\hline Definitive discontinuation of $1^{\text {st }}$-line therapy & $564(83.7)$ & $109(86.5)$ & 0.17 \\
\hline Main reason of definitive discontinuation of $1^{\text {st }}$-line therapy ${ }^{a}$ & & & 0.27 \\
\hline Progressive disease & $432(76.6)$ & $79(72.5)$ & \\
\hline Poor tolerability & $57(10.1)$ & $9(8.3)$ & \\
\hline Death & $27(4.8)$ & $10(9.2)$ & \\
\hline Physician decision & $27(4.8)$ & $4(3.7)$ & \\
\hline Other & $15(2.7)$ & $6(5.5)$ & \\
\hline Missing data & $6(1.1)$ & $1(0.9)$ & \\
\hline Premature discontinuation of targeted therapy & $88(13.1)$ & $11(8.7)$ & 0.20 \\
\hline $\begin{array}{l}\text { Main reason of definitive discontinuation of targeted } \\
\text { therapy }^{a}\end{array}$ & & & 0.64 \\
\hline Poor tolerability & $55(62.5)$ & $8(72.7)$ & \\
\hline Other & $31(35.2)$ & $3(27.3)$ & \\
\hline Missing data & $2(2.3)$ & $0(0.0)$ & \\
\hline At least one metastasectomy & $166(24.6)$ & $20(15.9)$ & $\mathbf{0 . 0 3}$ \\
\hline Initiation of a second-line therapy ${ }^{a}$ & $428(67.1)$ & $70(58.8)$ & 0.08 \\
\hline Same targeted therapy & $119(27.8)$ & $24(34.3)$ & \\
\hline Change of targeted therapy & $172(40.2)$ & $22(31.4)$ & \\
\hline Chemotherapy alone & $136(31.8)$ & $23(32.9)$ & \\
\hline Radiotherapy alone & $0(0.0)$ & $1(1.4)$ & \\
\hline Missing data & $1(0.1)$ & $0(0.0)$ & \\
\hline
\end{tabular}


Table 2. Continued

\begin{tabular}{lccc}
\hline \multicolumn{1}{c}{ Characteristics, $\boldsymbol{n}(\boldsymbol{\%})$} & $\begin{array}{c}\text { Patients aged } \\
\mathbf{4 5} \text { years, } \mathbf{n = 6 7 4}\end{array}$ & $\begin{array}{c}\text { Patients aged } \\
\mathbf{7 5} \text { years, } \mathbf{n = 1 2 6}\end{array}$ & $\boldsymbol{p}$ \\
\hline At least one any grade adverse event & $662(98.2)$ & $123(97.6)$ & 0.72 \\
Blood and lymphatic system disorders & $557(82.6)$ & $106(84.1)$ & 0.68 \\
Cardiovascular disorders & $166(24.6)$ & $33(26.2)$ & 0.71 \\
Gastrointestinal disorders & $543(80.6)$ & $102(81.0)$ & 0.92 \\
Nervous system disorders & $252(37.4)$ & $30(23.8)$ & $\mathbf{0 . 0 0 3}$ \\
Skin and subcutaneous tissue disorders & $371(55.0)$ & $55(43.7)$ & $\mathbf{0 . 0 2}$ \\
At least one grade 3 or 4 adverse event & $349(51.8)$ & $67(53.2)$ & 0.77 \\
Blood and lymphatic system disorders & $142(21.1)$ & $24(19.1)$ & 0.61 \\
Cardiovascular disorders & $32(4.8)$ & $9(7.1)$ & 0.26 \\
Gastrointestinal disorders & $117(17.4)$ & $23(18.3)$ & 0.81 \\
Nervous system disorders & $30(4.5)$ & $2(1.6)$ & 0.13 \\
Skin and subcutaneous tissue disorders & $57(8.5)$ & $12(9.5)$ & 0.70 \\
\hline${ }^{a}$ Among those concerned & & &
\end{tabular}

${ }^{a}$ Among those concerned 
Table 3. Factors associated with death in the STROMBOLI cohort according to multivariable Cox analyses

\begin{tabular}{llc}
\hline & $\begin{array}{c}\text { Event vs no event, HR } \\
{[\mathbf{9 5 \%} \mathbf{C I}]}\end{array}$ & $\boldsymbol{p}$ \\
\hline ECOG-PS & 1 & $<\mathbf{0 . 0 0 0 1}$ \\
0 & $1.52[1.18-1.96]$ & \\
1 & $2.92[2.15-3.97]$ & $\mathbf{0 . 0 0 4 4}$ \\
$\geq 2$ & & \\
Hemoglobin & 1 & $\mathbf{0 . 0 0 0 5}$ \\
$\quad$ Normal & $1.39[1.11-1.75]$ & \\
$\quad$ Abnormal & & \\
Alkaline phosphatases & 1 & \\
$\quad$ Normal & $1.55[1.22-1.99]$ \\
$\quad$ Abnormal & & \\
\hline adjusted on age and sex; ECOG-PS: eastern cooperative oncology group performance status; HR: hazard ratio; 95\% CI: 95\% \\
confidence intervals; vs: versus
\end{tabular}


Table 4. Factors associated with progression or death in the STROMBOLI cohort according to multivariable Cox analyses

\begin{tabular}{|c|c|c|}
\hline & $\begin{array}{c}\text { Event vs no event, } \text { HR }^{\mathrm{a}} \\
{\left[\begin{array}{lll}95 \% & \mathrm{CI}\end{array}\right]}\end{array}$ & $p$ \\
\hline ECOG-PS & & $<0.0001$ \\
\hline 0 & 1 & \\
\hline 1 & $1.19[0.99-1.43]$ & \\
\hline$\geq 2$ & $1.72[1.34-2.20]$ & \\
\hline Lung metastases & & $<0.0001$ \\
\hline No & 1 & \\
\hline Yes & $1.43[1.20-1.71]$ & \\
\hline Hemoglobin & & 0.0212 \\
\hline Normal & 1 & \\
\hline Abnormal & $1.22[1.03-1.45]$ & \\
\hline Creatinine clearance & & 0.0493 \\
\hline Normal & 1 & \\
\hline Abnormal & $1.24[1.00-1.54]$ & \\
\hline
\end{tabular}

